\title{
Calcium Accumulating Ability of Mitochondria from Bovine Coronary Artery

\author{
Comparison with Aortic Mitochondria
}

Satoshi Takeo, Ph.D. and Matao Sakanashi, M.D.

\section{SUMmaRY}

The calcium accumulating ability of mitochondria isolated both from bovine coronary artery and aorta was investigated. Coronary artery and aorta were pretreated with $0.1 \%$ collagenase. Cytochrome c oxidase activities of mitochondria isolated from coronary artery and aorta showed 25-fold and 19-fold increases, respectively, as compared with those of each homogenate, whereas NADPH-cytochrome $c$ reductase, potassium-phosphatase and $\mathrm{Na}^{+}$$\mathrm{K}+$ ATPase activities increased less than 2-fold. This suggests that the isolation procedure is capable of obtaining a subcellular fraction highly enriched with mitochondria.

Mitochondrial calcium uptake activity of the coronary artery was approximately 250 nmoles $\mathrm{Ca}^{2+} / \mathrm{mg}$ protein $/ 10 \mathrm{~min}$, and was markedly depressed with metabolic inhibitors such as $\mathrm{NaN}_{3}$, ruthenium red and 2,4-dinitrophenol. Calcium uptake activity of bovine aortic mitochondria showed similar activity and a similar trend in sensitivity to metabolic inhibitors. By contrast, the onset of the calcium binding reaction of the aortic mitochondria was slower and the azide-sensitivity of the mitochondria to magnesium ATPase activity was lower than those for coronary artery mitochondria. The present study has provided a method for isolation of mitochondria with a high capacity of calcium uptake activity, which may prove meaningful for future physiological and pharmacological evaluation of mitochondrial calcium accumulation in vascular smooth muscle.

\section{Additional Indexing Words:}

Aorta Calcium binding Calcium uptake Coronary artery Mitochondria

From the Department of Pharmacology, School of Medicine, Faculty of Medicine, University of the Ryukyus, Okinawa 903-01, Japan.

Address for reprint: Matao Sakanashi, M.D., Department of Pharmacology, Faculty of Medicine, University of the Ryukyus, Okinawa 903-01, Japan.

Received for publication November 17, 1983.

Manuscript revised March 5, 1984. 
T $T$ is well established that calcium ions play a critical role in regulating both striated and smooth muscle contraction. In striated muscle, the sarcoplasmic reticulum is well developed and considered to be an important source for intracellular free calcium during excitation-contraction coupling." ${ }^{\prime \prime}$ However, the sarcoplasmic reticulum of some vascular smooth muscle is poorly developed, ${ }^{2-4)}$ suggesting that some other subcellular organelles, such as the mitochondria and the cell membrane, may be important sources for intracellular calcium. There are several reports regarding calcium accumulation by mitochondria from rat and human myometrium, ${ }^{5,, 6)}$ bovine pulmonary artery and mesenteric artery, ${ }^{71}$ dog trachea ${ }^{81}$ and rabbit aorta. ${ }^{91}$ However, these reports provided less data concerning physiological and pharmacological characteristics of calcium accumulating ability of vascular smooth muscle than of cardiac muscle. Furthermore, characterization of mitochondria from the coronary artery has not been extensively demonstrated in the literature. ${ }^{9,10)}$ The present study was undertaken to explore the calcium accumulating ability of mitochondria from bovine coronary artery. For the purpose of comparison, the calcium accumulating ability of bovine aortic mitochondria, isolated under the same conditions, was also examined.

\section{Methods}

\section{Isolation of mitochondria}

Bovine heart and aorta were obtained from a slaughter house. It took 5-15 min to remove these tissues after exsanguination. The heart and aorta were put into cold saline and transferred to the laboratory. Fat and connective tissues were trimmed away from the aorta. About one third of the aortic adventitia was removed to eliminate the fat-enriched portion of the tissue. By contrast, the coronary artery was carefully isolated by supporting several branches of coronary artery such as the left circumflex, left anterior descending and right coronary arteries, with acrylic bars before trimming off the myocardium. After weighing the wet weight ( $6-8 \mathrm{Gm}$ of each tissue), the arteries were finely minced with scissors. The minced tissues were suspended in 3 volumes (estimated from the wet tissue weight) of a medium containing $120 \mathrm{mM} \mathrm{NaCl}, 5 \mathrm{mM} \mathrm{MgCl}_{2}, 1.25 \mathrm{mM} \mathrm{CaCl}_{2}$ and $20 \mathrm{mM}$ imidazole ( $\mathrm{pH} 7.4$ ). The suspension was preincubated at $37^{\circ} \mathrm{C}$ for $5 \mathrm{~min}$, and collagenase was added into the suspension to obtain a $0.1 \%$ collagenase solution. The suspension was incubated for $10 \mathrm{~min}$ at $37^{\circ} \mathrm{C}$, then chilled in an ice-cold bath $\left(0-4^{\circ} \mathrm{C}\right)$. The suspension was immediately centrifuged at $1,500 \times \mathrm{g}$ for 2 min, and supernatant was discarded. The resulting minced tissue was washed once with $0.25 \mathrm{M}$ sucrose $+10 \mathrm{mM}$ imidazole ( $\mathrm{pH} \mathrm{7.4)}$ and homogenized for 
5 sec by an Ultraturrax (Werke $A G$ ) at one third maximal speed. The homogenate was filtered through 2 layers of gauze, then the residual tissue was rehomogenized under the same conditions. The homogenate was combined with the previous filtrate (Fraction 1) and centrifuged at $1,500 \times \mathrm{g}$ for $15 \mathrm{~min}$. The supernatant was filtered again through 4 layers of gauze to eliminate fat and then centrifuged at $12,000 \times \mathrm{g}$ for $20 \mathrm{~min}$. The sediment (Fraction 2) was gently suspended in $0.25 \mathrm{M}$ sucrose $-1 \mathrm{mM}$ EDTA $-0.5 \%$ albumin $(\mathrm{pH} 7.0)$ and centrifuged at $10,000 \times \mathrm{g}$ for $10 \mathrm{~min}$. The resulting pellet (Fraction 3) or Fraction 2 was finally suspended in $0.25 \mathrm{M}$ sucrose $-10 \mathrm{mM}$ imidazole $(\mathrm{pH} 7.0$ ) at a concentration of $1.0-1.5 \mathrm{mg} / \mathrm{ml}$, and employed for assay of mitochondrial biochemical activity. The isolation procedure was carried out at $0-4^{\circ} \mathrm{C}$. Further washing of Fraction 3 with a medium containing either $0.25 \mathrm{M}$ sucrose $-1 \mathrm{mM}$ EDTA $-0.5 \%$ albumin, or $0.25 \mathrm{M}$ sucrose $-10 \mathrm{mM}$ imidazole did not produce an appreciable increase in the biochemical activity of mitochondria. Treatment of Fraction 2 with a medium containing $0.18 \mathrm{M} \mathrm{KCl}-10 \mathrm{mM}$ EDTA $-0.5 \%$ albumin $(\mathrm{pH} 7.0)$, which has been commonly employed for isolation of heart mitochondria, ${ }^{12}$ ) attenuated the calcium accumulating activity for mitochondria of the vascular smooth muscle.

\section{Measurements of marker enzyme activity}

Measurements of marker enzyme activity were performed according to methods described elsewhere. ${ }^{13)-18)}$ For this purpose, each fraction was well homogenized again to explore latent activities. Cytochrome $\mathrm{c}$ oxidase activity was estimated by the method of Wharton and Tzagoloff, ${ }^{13)}$ and the activity was expressed as the estimated first-order velocity constant (nmoles cytochrome/ $\mathrm{min} / \mathrm{mg}$ protein). NADPH-cytochrome $\mathrm{c}$ reductase activity (nmoles NADPH/ $\mathrm{min} / \mathrm{mg}$ protein) was determined by the method of Masters et al. ${ }^{14}$ ) The measurement of potassium-stimulated phosphatase (nmoles nitrophenol/min/ mg protein) was performed by the method of Lamers et al. ${ }^{15)} 5^{\prime}$-Nucleotidase ${ }^{16)}$ and ouabain-sensitive $\mathrm{Na}^{+}-\mathrm{K}^{+}$ATPase $^{17)}$ activities were estimated by determining inorganic phosphate liberated during incubation according to the method of Taussky and Shorr. ${ }^{18)}$ The activities are shown as nmoles $\mathrm{Pi} / \mathrm{min} /$ $\mathrm{mg}$ protein. Protein concentrations were determined by the method of Lowry et al. ${ }^{19)}$

\section{Measurements of ATPase activity}

The ATPase assay was performed according to the method described elsewhere. ${ }^{20 !}$ Magnesium-dependent ATPase (Mg-ATPase) activity was measured in a medium containing $100 \mathrm{mM} \mathrm{KCl}, 20 \mathrm{mM}$ Tris- $\mathrm{HCl}, 10 \mathrm{mM}$ $\mathrm{MgCl}_{2}, 0.2 \mathrm{mM}$ EGTA, $4 \mathrm{mM}$ Tris-ATP and about $0.1 \mathrm{mg}$ protein ( $\mathrm{pH} 6.8$ ). After 3 min-preincubation, the reaction was initiated by adding $4 \mathrm{mM}$ ATP 
and, after $5 \mathrm{~min}$ of incubation, terminated by adding $12 \%$ trichloroacetic acid. The resulting mixture was centrifuged at $4^{\circ} \mathrm{C}$ at $1,000 \times \mathrm{g}$ for $10 \mathrm{~min}$ and the supernatant was sampled for estimation of inorganic phosphate according to the method of Taussky and Shorr. ${ }^{18)}$ Total ATPase activity was measured by the same procedure as $\mathrm{Mg}$-ATPase activity except that $0.1 \mathrm{mM}$ $\mathrm{CaCl}_{2}$ was substituted for $0.2 \mathrm{mM}$ EGTA. The difference in the activities between the total ATPase and the Mg-ATPase was taken as calcium-stimulated, magnesium-dependent ATPase (Ca-ATPase) activity. Mg-ATPase activity was also measured in the presence of $5 \mathrm{mM} \mathrm{NaN}_{3}$ in order to determine the azide-sensitivity of Mg-ATPase.

Calcium accumulating activity

The measurement of calcium accumulating activity was performed by a method described elsewhere. ${ }^{20)}$ Calcium binding activity was measured at $25^{\circ} \mathrm{C}$ for $10 \mathrm{~min}$ in a medium containing $10 \mathrm{mM} \mathrm{KGl}, 20 \mathrm{mM}$ Tris- $\mathrm{HCl}$, $10 \mathrm{mM} \mathrm{MgCl}_{2}, 4 \mathrm{mM} \mathrm{Na}-\mathrm{ATP}, 0.1 \mathrm{mM}^{45} \mathrm{CaCl}_{2}$ and about $0.15 \mathrm{mg}$ protein ( $\mathrm{pH}$ 6.8), unless otherwise mentioned. The measurement of calcium uptake activity was conducted at $37^{\circ} \mathrm{C}$ for $10 \mathrm{~min}$ in a medium containing $10 \mathrm{mM}$ $\mathrm{KCl}, 20 \mathrm{mM}$ Tris- $\mathrm{HCl}, 10 \mathrm{mM} \mathrm{MgCl}_{2}$, $4 \mathrm{mM} \mathrm{Na}$-ATP, $0.1 \mathrm{mM}{ }^{45} \mathrm{CaCl}_{2}$, about $0.15 \mathrm{mg}$ protein and permeant ion(s) such as either $4 \mathrm{mM}$ potassium oxalate or $4 \mathrm{mM}$ succinate $+4 \mathrm{mM} \mathrm{KH}_{2} \mathrm{PO}_{4}(\mathrm{pH} 6.8)$. The reaction was initiated by adding ${ }^{45} \mathrm{CaCl}_{2}$ and terminated by Millipore filtration methods described elsewhere. ${ }^{20}$ Calcium uptake activity was also estimated in the presence of metabolic inhibitors such as $\mathrm{NaN}_{3}$, ruthenium red and dinitrophenol. Both calcium binding and uptake activities were measured in the same manner as above, under different concentrations of ATP $(0.3$ to $4 \mathrm{mM})$ and $\mathrm{CaCl}_{2}$ (5 to $100 \mu \mathrm{M}$ ), incubation times ( 2 to $30 \mathrm{~min}$ ) and $\mathrm{pH}(6.5$ to 7.8 ). Less than $10 \%$ of ATP added to the medium was consumed in the assay.

\section{Statistical methods and reagents employed}

The Student's t-test was used for comparison of the values for coronary artery with those for aorta. Differences at the $95 \%$ confidence level were considered significant. Reagents employed in the present experiment were collagenase (Type I: Sigma Co.), protease (Nagarse, Nagase Sangyo), ruthenium red (Sigma Co.), 2, 4-dinitrophenol (Sigma Co.) and cytochrome c(Type III: Sigma Co.). ${ }^{45} \mathrm{CaCl}_{2}$ was purchased from the Japan Radioisotope Reagent Association.

\section{Results}

Preliminary study

Cytochrome $\mathrm{c}$ oxidase activity was used as a marker for the mitochon- 
drial fraction in the present experiments. First, two commercially available enzymes, collagenase and protease (Nagarse) were employed to soften the vascular smooth muscle, since tissue rigidity is one of the most difficult problems for isolation of subcellular fractions. The coronary artery was treated for $10 \mathrm{~min}$ at $37^{\circ} \mathrm{C}$ either with $0.1 \%$ collagenase or $0.1 \%$ protease, or without any enzymes (non-treatment). The cytochrome c oxidase activities of Fraction 3 from the coronary artery treated with collagenase, protease and without enzymes were 622, 580 and 501 nmoles/min/mg protein, respectively (mean values of 2 experiments). When the tissue was incubated for longer than $15 \mathrm{~min}$ or shorter than $10 \mathrm{~min}$ at $37^{\circ} \mathrm{C}$, the cytochrome c oxidase activity of Fraction 3 was found to be lower than that at a 10 min-incubation. A similar trend in the cytochrome c oxidase activity was found for Fraction 3 from the bovine aorta. Thus, we employed a 10 min-incubation with $0.1 \%$ collagenase at $37^{\circ} \mathrm{C}$ for the pretreatment of the vascular smooth muscle.

\section{Marker enzyme study}

In the first set of experiments, a marker enzyme study was performed using different fractions obtained in the isolation procedure for mitochondria (Table I). NADPH-cytochrome c reductase activity was employed as a marker for the microsomal fraction. ${ }^{11)} \quad 5^{\prime}$-Nucleotidase activity is found in the microsomal fraction and/or sarcolemmal fraction, ${ }^{21)}$ whereas potassium phosphatase and ouabain-sensitive $\mathrm{Na}^{+}-\mathrm{K}^{+}$ATPase activities are considered to be specific for the sarcolemmal fraction. Control values for cytochrome c oxidase

Table I. Marker Enzyme Activities and Protein Yield of Fractions Obtained from the Isolation Procedure for Mitochondria

\begin{tabular}{|c|c|c|c|c|c|c|}
\hline & \multicolumn{2}{|c|}{ Fraction 1} & \multicolumn{2}{|c|}{ Fraction 2} & \multicolumn{2}{|c|}{ Fraction 3} \\
\hline & $\begin{array}{l}\text { Coronary } \\
\text { artery }\end{array}$ & Aorta & $\begin{array}{l}\text { Coronary } \\
\text { artery }\end{array}$ & Aorta & $\begin{array}{l}\text { Coronary } \\
\text { artery }\end{array}$ & Aorta \\
\hline Cytochrome c oxidase & $24 \pm 3$ & $25 \pm 3$ & $550 \pm 64$ & $470 \pm 46$ & $595 \pm 50$ & $490 \pm 52$ \\
\hline $\begin{array}{l}\text { NADPH-cytochrome } \\
\text { c reductase }\end{array}$ & $136 \pm 12$ & $186 \pm 15$ & $238 \pm 19$ & $244 \pm 18$ & $172 \pm 15$ & $213 \pm 16$ \\
\hline $5^{\prime}-$ Nucleotidase & $33+1$ & $32 \pm 4$ & $52 \pm 11$ & $78 \pm 11$ & $27 \pm 3$ & $34 \pm 3$ \\
\hline $\begin{array}{l}\mathrm{K}^{+} \text {-stimulated } \\
\text { phosphatase }\end{array}$ & $5 \pm 2$ & $5 \pm 2$ & $9 \pm 2$ & $10 \pm 1$ & $6 \pm 1$ & $7 \pm 2$ \\
\hline $\mathrm{Na}^{+}-\mathrm{K}^{+}$ATPase & $18 \pm 4$ & $19 \pm 2$ & $12 \pm 1$ & $15 \pm 1$ & $17 \pm 5$ & $22 \pm 4$ \\
\hline Protein yield & & & $\begin{array}{r}0.092 \\
\pm 0.010\end{array}$ & $\begin{array}{r}0.101 \\
\pm 0.010\end{array}$ & $\begin{array}{r}0.084 \\
\pm 0.009\end{array}$ & $\begin{array}{r}0.091 \\
\pm 0.009\end{array}$ \\
\hline
\end{tabular}

Units of the activities were as follows: Cytochrome c oxidase (nmoles cytochrome/min/mg protein), NADPH-cytochrome $\mathrm{c}$ reductase (nmoles $\mathrm{NADPH} / \mathrm{min} / \mathrm{mg}$ protein), 5'-nucleotidase (nmoles $\mathrm{Pi} / \mathrm{min} / \mathrm{mg}$ protein), $\mathrm{K}^{+}$-stimulated phosphatase (nmoles nitrophenol/min $/ \mathrm{mg}$ protein), $\mathrm{Na}^{+}-\mathrm{K}^{+}$ATPase (nmoles $\mathrm{Pi} / \mathrm{min} / \mathrm{mg}$ protein). Each value of the enzyme activitics represents a mean \pm S.E.M. of 4-6 experiments. Protein yield was expressed as a percentage $\mathrm{mg}$ protein yield, to the initial tissue wet weight $(n=12)$. 
activity of Fraction 3 (mitochondrial fraction) from bovine coronary artery were approximately one sixth of the values for bovine heart mitochondria (3.62 $\mu \mathrm{moles} / \mathrm{min} / \mathrm{mg}$ protein, a mean value of 2 experiments). The cytochrome c oxidase activity of Fraction 3 from coronary artery was approximately 25 times higher than the value for the homogenate, whereas that of aorta was 19 times. By contrast, increases in NADPH-cytochrome c reductase activity of Fraction 3 of both coronary artery and aorta increased to less than 2 times, compared with values for the homogenate. The NADPH-cytochrome $c$ reductase activity, measured in the presence of $1 \mu \mathrm{M}$ rotenone, was slightly depressed $(7 \%)$. Furthermore, 5'-nucleotidase and potassium-stimulated phosphatase activities of Fraction 3 in both tissues were almost the same as in the homogenates. $\mathrm{Na}^{+}-\mathrm{K}^{+}$ATPase activities of Fraction 3 of coronary artery and aorta were also similar to those for the homogenate. Treatment of the crude mitochondrial fraction (Fraction 2) with a buffer containing sucrose, EDTA and albumin elicited an increase in cytochrome c oxidase activity, whereas NADPH-cytochrome c reductase and $5^{\prime}$-nucleotidase activities were decreased by the treatment. The protein yield of Fraction 3 from bovine coronary artery was almost identical to that from the coronary artery, and extremely low as compared with the protein yield for rat heart muscle mitochondria $(0.22 \pm 0.01 \%, \mathrm{n}=10) .^{20)}$

\section{A T Pase activity}

As shown in Table II, the mitochondrial Mg-ATPase activity of the aorta was significantly higher than that of the coronary artery (30\% higher). However, the mitochondrial Ca-ATPase activity of the aorta was essentially identical to that of the coronary artery. The Mg-ATPase activity of the aorta, measured in the presence of $5 \mathrm{mM} \mathrm{NaN}_{3}$, was almost identical to that of the coronary artery. However, the ratio of azide-sensitivity to Mg-ATPase activity of coronary artery mitochondria was $83-100 \%$; the value for the aorta

Table II. ATPase Activities of the Mitochondrial Fraction (Fraction 3) from the Bovine Coronary Artery and Aorta

\begin{tabular}{c|c|c}
\hline & Coronary artery & Aorta \\
\hline Mg-ATPase & $153 \pm 13$ & $199 \pm 16^{*}$ \\
Ca-ATPase & $20 \pm 6$ & $24 \pm 6$ \\
Azide-sensitive & $144 \pm 3$ & $131 \pm 32$ \\
Mg-ATPase & $(93 \pm 2 \%)$ & $(66 \pm 2 \%)^{*}$
\end{tabular}

The Mg-ATPase and Ca-ATPase activities were measured in the presence of $10 \mathrm{mM} \mathrm{MgCl}_{2}$, and $10 \mathrm{mM} \mathrm{MgCl}_{2}-0.1 \mathrm{mM} \mathrm{CaCl}$, respectively. The activities were expressed as nmoles $\mathrm{Pi} / \mathrm{min} /$ $\mathrm{mg}$ protein.

* Significantly different from the coronary groups. Each value represents a mean \pm S.E.M. of 6 experiments. 


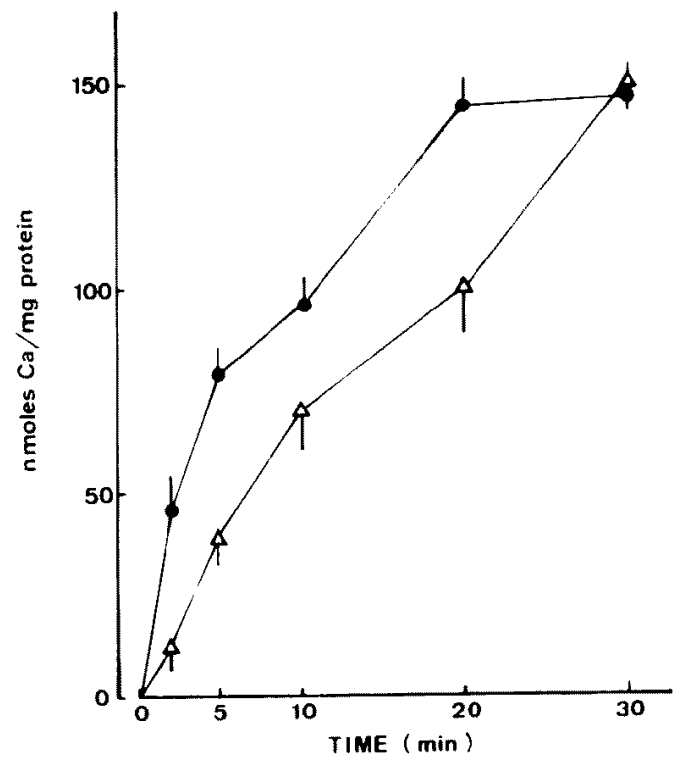

Fig. 1. Calcium binding activity of the mitochondrial fraction isolated from coronary artery $(O)$ and aorta $(\Delta)$ at different incubation times (nmoles $\mathrm{Ca}^{2+} / \mathrm{mg}$ protein). The incubating conditions are described in the methods section. Each value represents a mean \pm S.E.M. of 5 experimcnts.

was 55-70\%. The Mg-ATPase activities of Fraction 2 from coronary artery and aorta were 15-21\% lower than the values from Fraction 3.

Calcium binding activity

Mitochondrial calcium binding activities of both coronary artery and aorta at times of incubation ranging from 0 to $30 \mathrm{~min}$ are shown in Fig. 1 . The calcium binding activity of coronary artery mitochondria showed a rapid rise after the onset of incubation and reached the maximal level after a 20 min-incubation. The calcium binding activity of aortic mitochondria increased in an almost linear manner for incubation times up to $30 \mathrm{~min}$, but it was significantly lower during $20 \mathrm{~min}$ of incubation than the coronary artery mitochondria. Since the calcium binding of aortic mitochondria at $45 \mathrm{~min}$ incubation was approximately 170 nmoles $\mathrm{Ca}^{2+} / \mathrm{mg}$ protein, the activity appears to be saturable. In the absence of ATP in the incubation medium, the calcium binding activities of coronary artery and aortic mitochondria were $28 \pm 4$ and $16 \pm 2$ nmoles $\mathrm{Ca}^{2+} / \mathrm{mg}$ protein $/ 10 \mathrm{~min}$, respectively $(\mathrm{n}=4)$.

Calcium uptake activity

a) Effects of permeant ions and incubation time

The calcium uptake activities of coronary artery and aortic mitochondria were measured at different times of incubation in the presence of either $4 \mathrm{mM}$ oxalate or $4 \mathrm{mM}$ succinate $+4 \mathrm{mM} \mathrm{KH}_{2} \mathrm{PO}_{4}$ (Fig. 2). In the presence of 


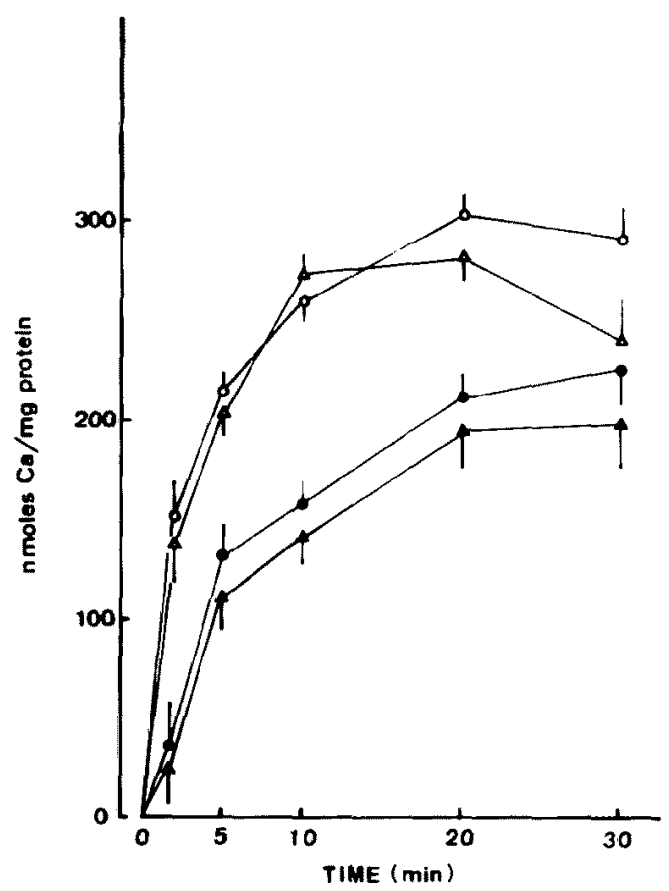

Fig. 2. Calcium uptake activity of the mitochondrial fraction isolated from the coronary artery $(O)$ and aorta $(\triangle)$ at different times of incubation. in the presence of $4 \mathrm{mM}$ succinate $+4 \mathrm{mM} \mathrm{KH}_{2} \mathrm{PO}_{4}$, and from the coronary artery ( $)$ and aorta $(\boldsymbol{A})$ in the presence of $4 \mathrm{mM}$ potassium oxalate (nmoles $\mathrm{Ca}^{2+} / \mathrm{mg}$ protein). Each value represents a mean \pm S.E.M. of 5 experiments.

oxalate, the calcium uptake activity of coronary artery mitochondria was slightly higher than that of aortic mitochondria. In the presence of succinate + phosphate, the calcium uptake activities of both coronary artery and aortic mitochondria were essentially identical except for the values at 30 min-incubation, where the activity of aorta was lower than that of coronary artery fraction. Calcium uptake by mitochondria from both coronary artery and aorta in the presence of succinate+ phosphate was of rapid onset and high capacity in comparison with that in the presence of oxalate. The calcium uptake activity of coronary artery and aortic mitochondria was found to be saturable after 20 or $30 \mathrm{~min}$ of incubation. The calcium uptake activity of Fraction 2 was $70-93 \%$ of the Fraction 3 value.

\section{b) Effects of $\mathrm{CaCl}_{2}$ concentration}

The calcium uptake activity of mitochondria isolated from bovine coronary artery and aorta was also measured in the medium containing various concentrations of $\mathrm{CaCl}_{2}$ (Table III). There were no significant differences in the calcium uptake activity between coronary artery and aortic mitochondria at 5 to $100 \mu \mathrm{M}$ of $\mathrm{CaCl}_{2}$. 
Table III. Calcium Uptake Activities at Different Concentrations of $\mathrm{CaCl}_{2}$ of the Mitochondrial Fraction (Fraction 3) Isolated from the Bovine

Coronary Artery and Aorta

\begin{tabular}{|c|c|c|}
\hline $\mathrm{Ca}^{2+}\left(\mu^{\mathrm{M}}\right)$ & Coronary artery & Aorta \\
\hline 5 & $11.3 \pm 1.4$ & $11.4 \pm 1.0$ \\
\hline 10 & $23.4 \pm 2.2$ & $23.5 \pm 1.3$ \\
\hline 30 & $87.6 \pm 6.8$ & $71.7 \pm 6.5$ \\
\hline 50 & $147.4 \pm 8.0$ & $128.7 \pm 7.7$ \\
\hline 100 & $285.2 \pm 22.0$ & $263.0 \pm 12.3$ \\
\hline
\end{tabular}

The activities were measured for $10 \mathrm{~min}$ in the presence of $4 \mathrm{mM} \mathrm{ATP}, 10 \mathrm{mM} \mathrm{MgCl}_{2}$ and different concentrations of $\mathrm{CaCl}_{2}$, and expressed as nmoles $\mathrm{Ca}^{2+} / \mathrm{mg}$ protein $/ 10 \mathrm{~min}$.

Each value represents a mean \pm S.E.M. of $4-5$ experiments.

Table IV. Calcium Uptake Activities in the Presence of Metabolic Inhibitors of the Mitochondrial Fraction (Fraction 3) Isolated from the Bovine Coronary Artery and Aorta

\begin{tabular}{l|c|c|c|c|c}
\hline & Control & -ATP & $\mathrm{NaN}_{3}$ & Dinitrophenol & $\begin{array}{c}\text { Ruthenium } \\
\text { red }\end{array}$ \\
\hline Goronary artery & $254 \pm 16$ & $38 \pm 8$ & $23 \pm 5$ & $79 \pm 10$ & $5 \pm 2$ \\
Aorta & $266 \pm 20$ & $32 \pm 13$ & $14 \pm 4$ & $80 \pm 8$ & $21 \pm 5$
\end{tabular}

Mitochondrial calcium uptake activity was measured in the standard medium (methods section) in the presence of either $5 \mathrm{mM} \mathrm{NaN}_{3}, 0.1 \mathrm{mM}$ dinitrophenol or $1 / 1 \mathrm{M}$ ruthenium red, and in the absence of inhibitors (control) and ATP (-ATP). The activities were expressed as nmoles $\mathrm{Ca}^{2+} / \mathrm{mg}^{2}$ protein $/ 10 \mathrm{~min}$.

Each value represents a mean \pm S.E.M. of $4-5$ experiments.

\section{c) Effects of inhibitors}

The effects of inhibitors on mitochondrial calcium uptake activity were examined in the presence of $100 \mu \mathrm{M} \mathrm{CaCl}_{2}$ and succinate+phosphate (Table IV). The ATP-independent calcium uptake activities of coronary artery and aortic mitochondria were 15 and $12 \%$ of the ATP-dependent calcium uptake activity (control value). Incubation with $5 \mathrm{mM} \mathrm{NaN}_{3}$ showed a more than $90 \%$ inhibition in mitochondrial calcium uptake activity, while $0.1 \mathrm{mM}$ dinitrophenol depressed the calcium uptake activities of coronary artery and aortic mitochondria by approximately $70 \%$. The calcium uptake activities of coronary artery and aortic mitochondria were almost completely inhibited in the presence of $1 \mu \mathrm{M}$ ruthenium red. Furthermore, $0.1 \mu \mathrm{M}$ ruthenium red inhibited the calcium uptakc activity of coronary artery and aortic mitochondria by $67 \pm 4$ and $72 \pm 5 \%$, respectively $(n=5)$.

d) Effects of ATP concentration

Mitochondrial calcium uptake activity was measured in the presence of different concentrations of ATP (0.3 to $4 \mathrm{mM}$ ) (Fig. 3). Lineweaver-Burk 
plots of the results indicate that $\mathrm{K}_{\mathrm{m}}$ values for the calcium uptake activity of the coronary artery and aortic mitochondria were almost similar $\left(K_{m}=0.2 \mathrm{mM}\right.$ ATP), although the $\mathrm{V}_{\max }$ for aortic mitochondria (278 nmoles $\mathrm{Ca}^{2+} / \mathrm{mg}$ protein) was slightly higher than that of coronary artery mitochondria (260 nmoles $\mathrm{Ca}^{2+} / \mathrm{mg}$ protein) at an incubation time of $10 \mathrm{~min}$.

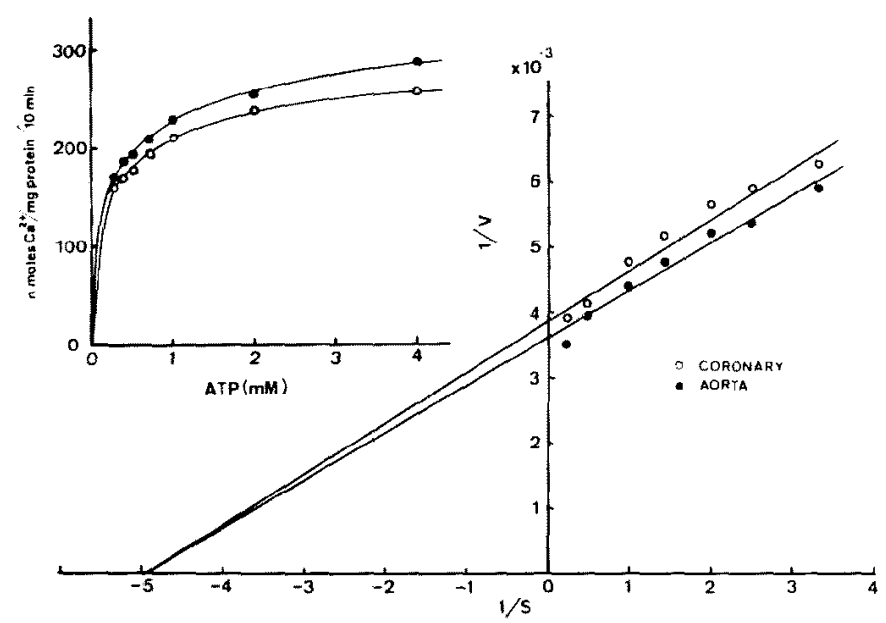

Fig. 3. Calcium uptake activity of the mitochondrial fraction isolated from the coronary artery $(O)$ and aorta $(O)$ at different concentrations of ATP (nmoles $\mathrm{Ca}^{2+} / \mathrm{mg}$ protein $/ 10 \mathrm{~min}$ ), and their Lineweaver-Burk plots. The reaction was carried out for $10 \mathrm{~min}$ in the presence of $0.1 \mathrm{mM} \mathrm{CaCl} \mathrm{Cl}_{2}$. The results were typical of 3 experiments.

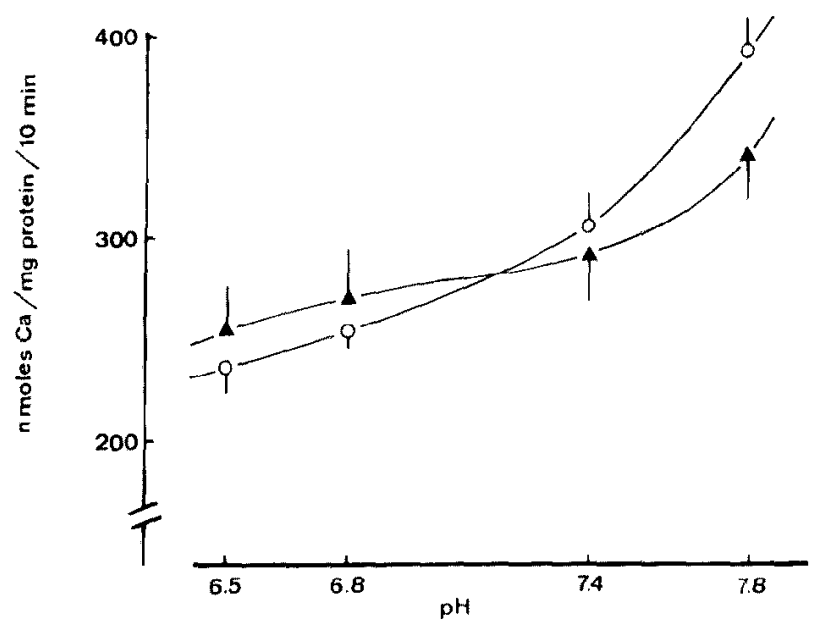

Fig. 4. Calcium uptake activity of the mitochondrial fraction isolated from the coronary artery $(O)$ and aorta $(\Delta)$ at different $\mathrm{pH}\left(\mathrm{nmoles} \mathrm{Ca}^{2+} / \mathrm{mg}\right.$ protein $/ 10 \mathrm{~min}$ ). The reaction was carried out for $10 \mathrm{~min}$ in the presence of $0.1 \mathrm{mM} \mathrm{CaCl}_{2}$. Each value represents a mean \pm S.E.M. of 4 experiments. 
e) Effects of $\mathrm{pH}$

Mitochondrial calcium uptake activities were measured in the incubation medium over $\mathrm{pH}$ values ranging from 6.5 to 7.8 , As shown in Fig. 4, the calcium uptake activities of mitochondria from the coronary artery increased with a rise in $\mathrm{pH}$ of the incubation medium, but the uptake of aortic mitochondria is almost similar up to $\mathrm{pH}$ 7.4. Calcium uptake activities of both coronary artery and aortic mitochondria tended to be higher at $\mathrm{pH} 7.8$ than at $\mathrm{pH}$ 7.4 .

\section{Discussion}

In preliminary studies, collagenase and protease were used for the pretreatment of smooth muscle tissue. Both enzyme treatments yielded purer mitochondrial fractions than the isolation without enzyme treatment on the basis of their cytochrome $c$ oxidase activities. The cytochrome c oxidase activity of Fraction 3 (mitochondrial fraction), isolated after pretreatment with collagenase, was slightly higher than with protease. Thus, smooth muscles were treated with $0.1 \%$ collagenase in the present studies. However, our results suggest that protease treatment may also represent a satisfactory procedure in the isolation of vascular smooth muscle mitochondria.

Since mitochondrial fractions isolated from the bovine heart by the method of Sordahl12) show about a 4-fold increase in cytochrome c oxidase activity as compared with the homogenate, the present results concerning marked increases in cytochrome c oxidase activity (19 to 25-fold) suggest that the isolation procedure employed in the present experiment provided a highly purified mitochondrial fraction. This was also supported by our findings that the increment in NADPH-cytochrome $\mathrm{c}$ reductase activity was only 2-fold and that $5^{\prime}$-nucleotidase and potassium-stimulated phosphatase activities were similar to values from crude homogenate. When Fraction 2 was washed with $0.25 \%$ sucrose $-1 \mathrm{mM}$ EDTA $-0.5 \%$ albumin, cytochrome c oxidase activity increased slightly, but NADPH-cy tochrome c reductase and $5^{\prime}$-nucleotidase activities decreased. This indicates that the washing procedure is necessary in order to obtain a fraction highly enriched with mitochondria. The cytochrome $\mathrm{c}$ oxidase activity of mitochondria derived from the coronary artery was higher than that from the aorta, suggesting that the mitochondrial fraction isolated from the coronary artery may be more enriched. This is also supported by our findings of a relatively low inhibitory action of $\mathrm{NaN}_{3}$ on the $\mathrm{Mg}$-ATPase activity of Fraction 3 derived from the aorta $(66 \%)$, as compared with the coronary artery fraction (93\%).

Zelick et al ${ }^{10 /}$ demonstrated that calcium uptake activity of mitochondria 
isolated from the pig coronary artery was about $20 \mathrm{nmoles} \mathrm{Ca}^{2+} / \mathrm{mg}$ protcin/ $10 \mathrm{~min}$, when measured at $25^{\circ} \mathrm{C}$ in the presence of $0.1 \mathrm{mM} \mathrm{CaCl}, 5 \mathrm{mM}$ ATP, $5 \mathrm{mM}$ oxalate and $5 \mathrm{mM} \mathrm{MgCl}_{2}$. Fitzpatrick et al ${ }^{9}$ reported that the net calcium uptake by mitochondrial fractions from rabbit aorta was about 25 nmoles $\mathrm{Ca}^{2+} / \mathrm{mg}$ protein $/ 10 \mathrm{~min}$, when measured at $37^{\circ} \mathrm{C}$ in the presence

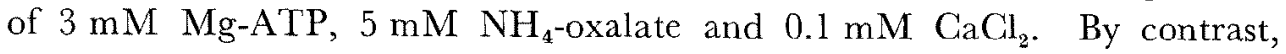
calcium uptake activities of mitochondria from both bovine coronary artery and aorta in the present experiments were 254 and $266 \mathrm{nmoles} \mathrm{Ca}^{2+} / \mathrm{mg}$ protein $/ 10 \mathrm{~min}$, respectively, when measured at $37^{\circ} \mathrm{C}$ in the presence of $4 \mathrm{mM}$

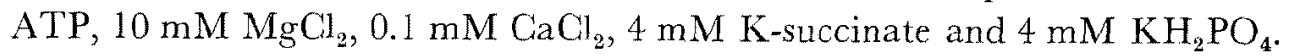
Although differences in incubating conditions and compositions, and species differences should be taken into consideration, it is noteworthy that the mitochondrial fraction isolated from bovine coronary artery and aorta showed very high calcium uptake activities as compared with mitochondrial fractions isolated from other vascular smooth muscle tissues. Thus, the present experimental procedure may provide a meaningful method for the evaluation of calcium accumulation of vascular smooth muscle mitochondria.

Takeo et $a^{20)}$ demonstrated that mitochondrial fraction isolated from the rat heart showed a $\mathrm{K}_{\mathrm{m}}$ of about $0.2 \mathrm{mM}$ ATP for calcium uptake activity: the calcium uptake activity was independent of $\mathrm{pH}$ in the incubation medium. In this respect, our findings on calcium uptake activity of vascular smooth muscle mitochondria revealed a similar $K_{m}$ value to rat heart mitochondria, but the dependency of mitochondrial calcium uptake on the $\mathrm{pH}$ of the medium was slightly different from that of the heart mitochondria.20)

Differences between the mitochondria derived from bovine coronary artery and aorta were seen in the rate of onset of activation of calcium binding and in the ratio of azide-sensitivity to $\mathrm{Mg}$-ATPase activity. Although these differences may be partly duc to different purity of these mitochondrial preparations, we cannot rule out the possibility that these data reflect different properties of the membrane per se. However, mitochondria derived from bovine coronary artery and bovine aorta displayed similar calcium uptake activity under normal incubating conditions, in the presence of inhibitors and at different concentrations of $\mathrm{CaCl}_{2}$. Thus, it is unlikely that marked differences in calcium accumulating ability exist between the two mitochondrial fractions. Nonetheless, responsiveness of the mitochondria to various pharmacological and biochemical agents and the mitochondrial alterations under a variety of pathophysiological conditions should be further examined to elucidate properties of mitochondria from bovine coronary artery and aorta. 


\section{REFERENCES}

1. Winegrad $\mathrm{S}$ : The intracellular site of ralcium activation of contraction in frog skeletal muscle. J Gen Physiol 55: 77, 1970

2. Devine CE, Somlyo AV, Somlyo AP: Sarcoplasmic reticulum and excitation-contraction coupling in mammalian smooth muscle. J Cell Physiol 52: 690, 1972

3. Somlyo AV, Somlyo AP: Strontium accumulation by sarcoplasmic reticulum and mitochondria in vascular smooth muscle. Science 174: 955,1971

4. Zelis R, Flaim SF: Calcium influx blockers and vascular smooth muscle: Do we really understand the mechanism? Ann Int Med 94: 124, 1981

5. Janis RA, Crankshaw DJ, Daniel EE: Control of intracellular $\mathrm{Ca}^{2+}$ activity in rat myometrium. Am J Physiol 232: C50, 1977

6. Janis RA, Lee EY, Allen J, Daniel EE: The role of sarcolemma and mitochondria in regulating $\mathrm{Ca}^{2+}$ movements in human myometrium. Pflüg Arch Eur J Physiol 365: 171, 1976

7. Somlyo AP, Vallieres J, Garfield RE, Shuman H, Scarpa A, Somlyo AV: Calcium compartmentalization in vascular smooth muscle. Electron probe analysis and studies on isolated mitochondria. in The Biochemistry of Smooth Muscle, ed by Stephen NL, University Park Press, Baltimore, p 563-583, 1977

8. Stephen NL, Kroeger EA, Wrogemann K: Energy metabolism. Methods in isolated smooth muscle and methods at cellular and subcellular levels. in Methods in Pharmacology, Vol 3, ed by Daniel EE, Paton DM, Plenum Press, New York, p 555-591, 1975

9. Fitzpatrick DF, Landon EJ, Debbas G, Hurwitz L: A calcium pump in vascular smooth muscle. Science 176: 305, 1972

10. Zelick U, Karnstedt U, Albrecht E: Calcium uptake and calcium release by subcellular fractions of smooth muscle. Acta Biol Med Germ 34: 981, 1975

11. Verity MA, Bevan JA: Membrane adenosine triphosphatase activity of vascular smooth muscle. Biochem Pharmacol 18: 327, 1969

12. Sordahl LA, Johnson C, Blailock ZR, Schwartz A: The mitochondrion. in Methods in Pharmacology, Vol 1, ed by Schwartz A, Appleton-Century-Crofts, New York, p 247-286, 1971

13. Wharton DC, Tzagoloff A: Cytochrome oxidase from beef heart mitochondria. in Methods in Enzymology, Vol 10, ed by Estabrook RW, Pullman ME, Academic Press, New York, p $245-250,1967$

14. Masters BSS, Williams $\mathrm{CH} \mathrm{Jr}$, Kamin H: The preparation and properties of microsomal TPNH-cytochrome c reductase from pig liver. in Methods in Enzymology, Vol 10, ed by Estabrook RW, Pullman ME, Academic Press, New York, p 565-573, 1967

15. Lamers JM, Stinis JT, Kort WJ, Hülsmann WC: Biochemical studies on the sarcolemmal function in hypertrophied rabbit heart. J Mol Cell Cardiol 10: 235, 1978

16. Heppel LA, Hilmoe RJ : 5'-Nucleotidases. in Methods in Enzymology, Vol 2, ed by Colowick SP, Kaplan NO, Acadcmic Press, New York, p 546-550, 1955

17. Takeo $S$, Fliegel L, Beamish RE, Dhalla NS: Effects of adrenochrome on rat heart sarcolemmal ATPase activities. Biochem Pahrmacol 29: 559, 1980

18. Taussky HH, Shorr $\mathrm{E}$ : A microcolorimetric method for the determination of inorganic phosphorus. J Biol Chem 202: 675, 1953

19. Lowry OH, Rosebrough NJ, Farr AL, Randall RJ: Protein measurement with the Folin phenol reagent. J Biol Chem 193: 265, 1951

20. Takeo S, Taam GML, Beamish RE, Dhalla NS: Effect of adrenochrome on calcium accumulation by heart mitochondria. Biochem Pharmacol 30: 157, 1981

21. Bodansky O, Schwartz MK: 5'-Nucleotidase. in Advances in Clinical Chemistry, Vol 11, ed by Bodansky O, Stewart CP, Academic Press, New York, p 277-328, 1968 